\title{
A FILOSOFIA DA EDUCAÇÃO IMPLÍCITA NA CAPOEIRA PENSADA A PARTIR DA LEI 10.639/03
}

\author{
Gustavo Arantes Camargo ${ }^{1}$ \\ Amanda Shütte ${ }^{2}$ \\ Dedicado ao Mestre Angolinha
}

Resumo: O presente texto se propõe a pensar a problemática afrobrasileira, em especial sua inserção no contexto escolar a partir da Lei 10.639/03, apresentando a capoeira como elo entre educação e cultura afrobrasileira. Esta abordagem será feita a partir de conceitos filosóficos, culturais e educacionais importantes como afroperspectivismo, ancestralidade, cultura oral e popular, assim como a questão da historicidade pensando sua relação com a capoeira.

Palavras-chave: Lei 10.639/03. Capoeira. África. Ancestralidade. Cultura popular.

Resumen: En este trabajo nos proponemos pensar temas afro-brasileños, en particular, su inclusión en el contexto de la escuela a partir de la Ley 10.639/03, tiendo la capoeira como un vínculo entre la educación y la cultura afro-brasileña. Este enfoque se tomará de conceptos filosóficos, culturales y educativos importantes como afroperspectivismo, ancestralidade, cultura oral y popular, así como la cuestión de la historicidad en su relación con la capoeira.

Palabras claves: Ley 10.639/03. Capoeira. África. Ancestralidade. Cultura popular.

\section{Introdução}

A promulgação da lei $10.639 / 03$, que se propõe a inserir no cotidiano escolar o ensino de história e cultura afrobrasileira e africana, coloca novos desafios ao cotidiano escolar. A vivência do meio escolar pela criança é considerada necessária para o desenvolvimento social de uma nação, mas a dificuldade de transformação das práticas nesse meio mostra também o viés conservador que o trespassa.

No livro "História e cultura africana e afro-brasileira na educação infantill, publicado pelo MEC em 2014, a capoeira aparece explicitamente como um

\footnotetext{
${ }^{1}$ Doutor em Filosofia pela PUC-Rio. Professor Adjunto de Filosofia da Educação da UFRJ-Macaé. Professor de Capoeira do Grupo de Capoeira Angolinha.

${ }^{2}$ Graduada em Educação Física pela UFRRJ. Mestra em Educação pela UFF. Professora do Colégio Estadual Euclydes da Cunha em Teresópolis e da Escola Municipal Maximino José Pacheco em Guapimirim. Treinel do Grupo de Capoeira Angolinha.
}

CAMARGO, Gustavo Arantes; SHÜTTE, Amanda. A filosofia da educação implícita na capoeira pensada a partir da lei 10.639/03. Revista Sul-Americana de Filosofia e Educação. Número 26: maio-out./2016, p. 25-40. 
programa a ser desenvolvido com crianças de 0 a 5 anos em creches e escolas do ensino fundamental. Nele a capoeira é entendida como capaz de ajudar na apresentação da história e cultura brasileira de origem africana de forma lúdica e, assim, contribuir para a diminuição do preconceito e na luta contra o racismo, tão presente em nossa cultura, por mais popular e negra que ela seja.

Neste livro de apoio, a capoeira é incentivada não em seu caráter desportivo ou marcial, e sim como atividade lúdica que visa apresentar às crianças a musicalidade e a movimentação natural própria à capoeira, assim como o universo cultural afro-brasileiro.

Neste artigo, apresentaremos a relação de alguns conceitos caros ao debate sobre cultura afrobrasileira com a capoeira e, ao final, apresentaremos o relato da experiência de um projeto de pesquisa e extensão em andamento sobre o tema.

\section{Pensar o afroperspectivismo e a ancestralidade a partir da capoeira}

O perspectivismo é uma ideia que cada vez mais tem conquistado espaço na filosofia. Sua força se deve à capacidade em oferecer uma alternativa razoável à antiquíssima dicotomia entre universalismo e relativismo. Sempre que se postula um valor, um conhecimento, uma forma como universal, cai-se na metafísica, que falha ao ser perguntada sobre o critério adotado para que este universal seja considerado universal. Não seria este universal apenas um particular universalizado? A opção contrária, o relativismo, mesmo sendo menos totalitária, nos traz não apenas a insegurança, mas o niilismo de uma total indiferenciação entre as opções, onde não haveria critérios de valoração possíveis, caindo tudo $e$ todos em um grande tanto faz.

O perspectivismo, ao afirmar que não é possível apreciar algo a não ser a partir de um ponto de vista particular e que este ponto nunca é o único, tende a se aproximar do relativismo. Porém, este ponto de vista deve ser explicitado e avaliado a partir da escolha assumida e justificada de critérios para tal. Neste sentido, o não apelo à universalidade não invalida o pensamento, pois o fato de todo pensamento ser perspectivo não significa que não possam ser comparados $e$ 
avaliados, não significa que tenham o mesmo valor. A busca por um critério de avaliação é a busca pelo valor dos valores.

Neste contexto de saída da metafísica e de avaliação de algo relativo, a história e a genealogia aparecem como fundamentais para pensar uma perspectiva. No caso deste lugar que hoje se chama Brasil, cuja metade da população é composta por pessoas negras, pode-se perguntar como os negros chegaram ao Brasil? Sabe-se que a resposta é a partir da escravização de tribos africanas por europeus a partir do século XVI. Os negros que aqui chegaram foram capturados na África e trazidos para esta terra para trabalhar como escravos no regime econômico imposto pela Europa aos demais continentes em meados do segundo milênio da era comum. Este fato histórico, a diáspora, já legitima a reivindicação de uma perspectiva africana para pensarmos a história e cultura do Brasil. Apresentar a cultura brasileira em uma afroperspectiva não significa universalizar a perspectiva africana, mas fazer com que ela seja reconhecida, fazer com que ganhe força.

O perspectivismo não aponta para o universal, mas para o pluriversal. Segundo RAMOSE (2011, p.10), o conceito de universo se origina do latim unius (um) e versus (alternativa). Para o autor, a palavra traz um duplo significado de um e de alternativa constituindo-se em uma contradição, onde a tradição dominante optou pela unidade ao invés da alternativa. Porém, haveria uma contradição lógica entre a ideia de universo como hoje a entendemos, como universal, $e$ a ideia de alternativa, que necessariamente aponta para outros pontos de vista. O filósofo propõe, então, pluriverso como forma de superar a contradição. Particularmente, não vemos a contradição lógica como o principal problema do conceito de universo. A partir do perspectivismo como crítica do universal, o conceito de pluriverso já se justifica como abertura a outras narrativas, muitas versões, muitas perspectivas.

Desta forma, o perspectivismo afirma o pluriverso, isto é, a pluralidade de alternativas e de versões sobre o cosmos, a vida, a ética, a história. Não havendo um centro nem um critério absoluto de veracidade. Aliás, dentro da lógica perspectivista, a veracidade é menos um critério de validação do conhecimento do 
que o resultado ela mesma de um constructo histórico-cultural. O que nos cabe, cremos, é produzir narrativas afroperspectivas da cultura brasileira, apresentando novos pontos de vista até então relegados ao esquecimento devido ao caráter de colonização ao qual o pensamento filosófico mundial foi submetido, uma vez que a expansão marítima europeia não foi apenas econômica, mas nossos sistemas de ensino e pensamento, incluindo a língua portuguesa, também foram impostos.

RAMOSE (2011) mostra como que a ideia de universalidade da filosofia europeia nada mais é, em relação à filosofia, do que uma perspectiva particular elevada à categoria de universal, excluindo as demais perspectivas como inválidas por serem elas "particulares". A isto, dá o nome de epistemicídio. Não há, é claro, problemas em se estudar filosofia clássica grega, o problema seria negar qualquer outra forma de pensamento como filosofia. O perspectivismo é uma forma de revaloração das epistemologias excluídas, dos pontos de vista perseguidos $e$ proibidos. A afirmação da ancestralidade africana para o brasileiro é, assim, um passo na descolonização de nosso pensamento.

Essa descendência africana de nossa cultura se apresenta bem na ideia de ancestralidade. Não se tratando, neste conceito, de reconstruir a África como ela foi ou é, segundo OLIVEIRA (2012, p.38):

A África por nós criada é em tudo mais africana que a África que perdura no continente negroide dos dias atuais. Optamos por essa escolha como ponto de partida: somos africanos ao nosso modo, o que nos regala uma singularidade única - pleonasmo mais que legítimo no jogo cultural que pretendemos empreender.

Esta recriação da África chama-se, para Oliveira, ancestralidade. Ancestralidade vai além do conceito e torna-se uma experiência cultural, um agir, uma postura ética, um criar-se e recriar-se a partir da diáspora. A ancestralidade aparece como reconhecimento por parte dos brasileiros de sua descendência africana, da descendência de sua cultura em relação àqueles que foram escravizados. Por demais os brasileiros somos europeizados $e$ hoje norteamericanizados. As culturas dominantes se fazem presentes no cotidiano. Marx e Engel, na "Ideologia Alemã", deixam claro que os valores dominantes em 
uma sociedade são os valores da classe dominante. Nesse contexto, a africanidade do Brasil, a ancestralidade, nos é escondida. Somos muito pouco chamados a pensar a negritude e a cultura como afrodescendentes.

Como contestar a africanidade, a afrodescendência da capoeira? A pergunta que melhor colocaria o problema é: por que contestar ou fingir que não existe afrodescendência na cultura popular? O preconceito é a única resposta. A recusa em se aceitar a olhar o Brasil em afroperspectiva aponta para o preconceito, por vezes inconsciente, que nos faz crer que nossa cultura é autóctone ou que decorre de um bom relacionamento entre os grupos europeu, indígena e negro.

Apesar de ser controverso o debate sobre a origem da capoeira, sua ancestralidade africana é incontestável, seja por aqueles que a defendem como preexistente na África, seja por aqueles que a entendem como tendo sido criada por negros africanos escravizados no Brasil.

A dúvida sobre a origem da capoeira persiste. $\mathrm{O}$ mais importante não é superar essa controvérsia, mas compreender que o princípio da capoeira é africano, ou seja, trata-se de uma construção dos africanos $e$ seus descendentes no contexto brasileiro, uma reelaboração da ancestralidade em outro tempo e lugar. (BRASIL, 2014, p. 87)

Historicamente, a capoeira se mostrou não apenas arma de resistência africana, escrava, negra, popular, mas também conquistou o respeito dos colonizadores, sendo chave-mestra de descolonização do pensamento branco, que, ao reconhecer o valor desta e de outras manifestações culturais afrodescendentes, reconhece sua própria ancestralidade africana e tem a chance de reconhecer $\mathrm{o}$ anterior eurocentrismo de seu paradigma supostamente universal.

Assim como aconteceu conosco, e com grande parte de nossos colegas, a capoeira nos serviu de porta de entrada a todo o universo (ou pluriverso) da cultura popular afrobrasileira. Após as rodas de capoeira, muitas vezes se faz um samba de roda. O samba de roda é desconhecido por boa parte dos brasileiros que podem conhecer rodas de samba, mas não o som do tambor, o canto de pontos $e$ as respostas do coro, além da dança e da umbigada do samba de roda. Não 
apenas o samba de roda é apresentado ao capoeirista neófito, mas um grande grupo de manifestações afrobrasileiras, onde uma puxa a outra e o respeito a todas é inevitável.

Mesmo sem uma pesquisa a respeito, arriscamos a hipótese de que a capoeira é a maior difusora da língua portuguesa no mundo. Os cantos de capoeira são cantados em português em qualquer país. Os capoeiristas do mundo inteiro aprendem o português e vêm ao Brasil. Porém, ninguém aprende português para ler José Saramago, lê-se traduções. A capoeira inverteu a relação de forças com seu dominador e hoje é a maior representante da língua que os colonizou.

Assumir parte da cultura brasileira como negritude afrodescendente é algo de extrema importância, pois esta é uma parcela muito rica de nossa cultura. A capoeira é uma prática cultural que nasceu à margem da sociedade brasileira. Foi criada por escravos africanos trazidos para o Brasil. Mesmo após a abolição da escravatura, apenas negros ex-escravos, caxinguelês (crianças que andavam com os capoeiras) e pessoas marginalizadas em geral a praticavam. Foi incluída no código penal em 1890, pelo decreto 847, de 11 de outubro do referido ano, no capítulo XIII: 'Dos vadios e capoeiras'. Somente na década de trinta do século seguinte a capoeira deixará de ser considerada oficialmente como crime. Por possuir esta raiz popular, a capoeira foi, durante a maior parte da história do Brasil, marginalizada e excluída dos âmbitos formais de educação da sociedade, fazendo com que seja importante, hoje, a sua inserção em ambientes acadêmicos, visando a reparação desta falta.

\section{Os conceitos de história e origem, um pensamento a partir de Walter Benjamin}

Neste ensaio falamos em afroperspectiva, isto é, em ancestralidade africana do Brasil. Ancestralidade é uma forma de pensar as origens da cultura brasileira. Origem aqui não aparece como o começo imaculado de um mundo perdido, ou o resgate de algo intacto que resolveria as questões do presente. Santos (2012, p. 49), falando de perspectividade e abertura para liberdade a partir do conceito de encruzilhada que propõe, afirma que "este movimento é interessante porque cair na armadilha da essência, da origem única, do centro, da lógica da identidade, 
enquanto conceito totalitário, constitui-se em reduzir as liberdades." Vimos que, para Oliveira (2012), há muito que não se trata de restaurar a verdade dos fatos ou do passado. Há muito que se sabe que a história é a historiografia daquilo que é e foi contado. Essa produção de África no Brasil é historicidade contemporânea.

O conceito de origem e a compreensão sobre história de Walter Benjamin, filósofo judeu alemão, que viveu na época da Segunda Guerra, que se suicidou ao tentar fugir da perseguição nazista, têm a nos ajudar em nosso pensamento. Também para Benjamin, a origem não é um ponto fixo e resgatável, e sim uma forma de pensar a temporalidade da história de uma forma diferente de como é pensada pela cultura dominante. "Articular historicamente o passado não significa conhecê-lo 'como ele de fato foi'”. (BENJAMIN, 1987, tese 6).

Para este autor, a história é contada pelos vencedores, que produzem assim uma narrativa linear, cronológica e causal sobre os acontecimentos, com pretensões de objetividade, dando a entender que o presente e suas relações de força são explicados e justificados a partir desta causalidade, justificando a dominação.

A historiografia burguesa, como Benjamin a define, tem a ideia de progresso em sua base. O progresso aponta para um movimento linear $e$ homogêneo do passado em direção ao futuro. $\mathrm{Na}$ crítica desenvolvida pelo filósofo, a temporalidade linear do progresso homogeneíza os acontecimentos criando uma narrativa onde a história perde sua intensidade e cada momento passa a ter o mesmo peso dos outros, um tempo homogêneo, vazio, escorrido $e$ sem intensidade.

A ideia de um progresso da humanidade na história é inseparável da ideia de sua marcha no interior de um tempo vazio e homogêneo. A crítica da ideia do progresso tem como pressuposto a crítica da ideia dessa marcha. (BENJAMIN, 1987, tese 13)

Criando uma alegoria a partir do quadro "Angelus novus" de Paul Klee, Benjamin diz que o anjo da história vê destruição aonde vemos progresso. "Onde nós vemos uma cadeia de acontecimentos, ele vê uma catástrofe única, que acumula incansavelmente ruína sobre ruína e as dispersa a nossos pés." 
(BENJAMIN, 1987, tese 9) Na metáfora, o anjo da história está voltado para o passado e vê nele apenas escombros de uma catástrofe única, seu desejo é recolher os restos da mesma e com eles compor a narrativa histórica. O passado se mostra como catástrofe para os vencidos. O historiador deveria debruçar-se sobre esses escombros e contar a história como catástrofe, mas é impelido para frente pela ideologia do progresso. Para Benjamin, a tarefa histórica seria redimir o passado recontando-o pela ótica dos vencidos, mas o progresso apresenta-se como uma ideologia de futuro que não nos permite conhecer nossa própria história.

$\mathrm{Na}$ perspectiva dos vencidos, só há caos, catástrofes, rupturas. As teses têm uma urgência: como construir um conceito de história que corresponda à verdade que, na tradição dos oprimidos, o estado de exceção é a regra geral; um inimigo nomeado: o conformismo da social-democracia; um alvo filosoficamente mais amplo: a crítica ao historicismo, presente em Benjamin desde $A$ origem do drama barroco alemão. (MURICY, K. 1999, p. 214)

Para contar a história como catástrofe é preciso pensar uma temporalidade intensiva e não cronológica a partir do conceito de origem, Ursprung. A origem é algo diferente de um começo ou gênese, é um salto para fora da história, um novo ponto, fora da lógica do progresso, trata-se de "parar o tempo para permitir o passado esquecido ou recalcado surgir de novo, e ser assim retomado e resgatado no atual." (GAGNEBIN, 1999, p. 10) O historiador se assemelharia mais a um colecionador de intensidades, de momentos, onde cada momento é único e contém a totalidade, como uma mônada. O conceito de origem é um ponto máximo de intensidade, explodindo a cronologia linear homogênea, pois é intensidade criadora. Em alemão ur Sprung, primeiro salto.

Para Benjamin é preciso recontar a história e, ao fazê-lo, recriamos o presente redimindo-o. $\mathrm{O}$ conceito de ancestralidade aparece como uma origem nesses termos, como uma forma de recontar a historia do Brasil em afroperspectiva. Este é o papel do conceito, apreender a ideia intensiva que salta para fora da história e instaura uma origem. A história do Brasil precisa ser recontada a partir de outras perspectivas. Recontar a história em afroperspectiva é recontá-la a contrapelo. É preciso uma constelação de ideias, de momentos, de 
origens, isto forma uma cultura, uma cultura histórica afrobrasileira. Esta é também uma tarefa educacional.

O conceito de história que aqui se propõe deve quebrar a ideia de linearidade e sentido pré-definido da mesma, criando pontos de intensidade que a reescrevam. Esta é a única possibilidade de se redimir o presente, a partir do momento em que a história puder ser contada em sua íntegra. A temporalidade burguesa não permite esta redenção, pois impele o homem, com uma força violenta, para o futuro em nome do progresso. O preço que a humanidade paga por este progresso é o preço de não poder falar de sua história.

Sem dúvida, somente a humanidade redimida poderá apropriar-se totalmente do seu passado. Isso quer dizer: somente para a humanidade redimida o passado é citável, em cada um dos seus momentos. (BENJAMIN, 1987, tese 3)

Ao não falar do passado, esconde-se também todas as barbaridades já realizadas em nome deste mesmo progresso. É neste sentido que Benjamin fala que não existe monumento da cultura que não seja monumento da barbárie. A capoeira nasce da barbárie da escravidão. Como falar da primeira sem falar da segunda? Desta forma, a capoeira já se apresenta como um recontar da história na perspectiva não dominante, na perspectiva não burguesa, na perspectiva afrobrasileira. A capoeira é a própria história do Brasil escrita a contrapelo da ideologia dominante.

Pensar a ancestralidade afrobrasileira é produzir intensidades temporais que recontem a história do Brasil, destacando personagens antes esquecidos pela historiografia oficial, celebrando o dia de Zumbi, por exemplo. Ancestralidade é a origem no sentido benjaminiano, não de começo imaculado, mas de novos começos intensivos, capazes de transformar o presente. É possível o estabelecimento de uma nova ligação entre passado e presente ao arrancar os fenômenos a uma ordem cronológica dita objetiva, uma vez que tal objetividade é uma construção arbitrária, a história contada pelos vencedores.

(...) a exigência de rememoração do passado não implica simplesmente a restauração do passado, mas também uma transformação do presente tal que, se o passado perdido aí 
for reencontrado, ele não fique o mesmo, mas seja, ele também, retomado e transformado. (GAGNEBIM, 1999, PÁG. 16)

Esta é a tarefa que está posta: recontar a história do Brasil a partir de uma perspectiva africana, assim como também indígena, redimindo seu passado, recriando origens, salvando o presente, fortalecendo a vida em suas diversas manifestações. "A tradição dos oprimidos nos ensina que o "estado de exceção" em que vivemos é na verdade a regra geral. Precisamos construir um conceito de história que corresponda a essa verdade.” (BENJAMIN, 1987, tese 8)

\section{Oralidade, narração e a educação na capoeira}

A "Coleção História da África" editada pela UNESCO, enfatiza, em vários momentos do livro sobre metodologias, o fato de que boa parte da cultura africana seja difundida pela tradição de cultura oral e por esta tenha se perpetuado.

Paralelamente às duas primeiras fontes da história africana (documentos escritos e arqueologia), a tradição oral aparece como repositório e o vetor do capital de criações socioculturais acumuladas pelos povos ditos sem escrita: um verdadeiro museu vivo. A história falada constitui um fio de Ariadne muito frágil para reconstituir os corredores obscuros do labirinto do tempo. Seus guardiões são os velhos de cabelos brancos, voz cansada e memória um pouco obscura, rotulados às vezes de teimosos e meticulosos (veilliesse oblige!): ancestrais em potencial... (ZERBO, 2010. P. XXXVIII)

Começamos a ver que a fala é apontada como um meio de propagação $e$ permanência da sabedoria dos ancestrais nas culturas de matriz africana, onde ficar mais velho é sinal de acúmulo de conhecimentos. "As tradições requerem um retorno contínuo à fonte." (ZERBO, 2010. p. 140) O historiador que buscar entender esta memória coletiva africana terá que se familiarizar com esta cultura.

Não é nossa intenção fazer historiografia africana, mas relacionar a oralidade à necessidade de se introduzir a história e a cultura afrobrasileira no contexto educacional brasileiro e pensar as relações internas a este processo. Neste sentido, a oralidade aparece presente também nas manifestações culturais populares, tendo o caso da capoeira como emblemático, uma vez que esta tradição 
se transmite pelo contato direto do discípulo com um mestre. "A tradição oral foi definida como testemunho transmitido de uma geração à outra." (ZERBO, 2010. p.140)

A relação de transmissão da cultura pela oralidade aparece também no texto "Experiência e pobreza" de Benjamin, onde se diz que, até a Segunda Guerra, a experiência de vida era comunicada aos jovens, era passada oralmente, de geração em geração $e$ isso se perdeu. A guerra foi uma experiência inconfessável, irrepassável. Os combatentes voltaram mudos: "Pois qual o valor de todo o nosso patrimônio cultural, se a experiência não mais o vincula a nós?" (BEJAMIN, 1987)

No texto "O narrador", o mesmo autor trata da narrativa e do narrador como personagens importantes do cotidiano cultural de um povo, mas também em vias de extinção. Novamente aponta a guerra como responsável por impedir a propagação da experiência de boca em boca entre as gerações. Esta transmissão é a história oral. Mesmo se referindo à Europa pós-guerra, suas ideias não nos impedem de pensar nosso contexto.

O papel do narrador e da cultura oral apontado pelo filosofo alemão se assemelha em muito ao papel desempenhado pelo mestre da capoeira ainda nos dias de hoje. "Professores e mestres são os principais agentes da capoeira. São eles que promovem e transmitem os fundamentos às gerações mais novas, que determinam os princípios, as normas, os valores e a filosofia que nortearão o seu trabalho e que influenciarão o comportamento e a formação dos seus alunos." (SILVA e HEINE, s/d, p. 116)

Para Benjamin as experiências estão deixando de ser comunicáveis, o conselho que depende da sabedoria do mais velho, depende da proximidade pessoal. Isto o leva a concluir que a sabedoria está em extinção. Esse processo se desenvolve junto com o capitalismo, que dá uma roupagem bonita ao novo e uma feia ao "velho", incentivando as pessoas a buscarem um retorno imediato. "O homem de hoje não cultiva o que não pode ser abreviado." (BEJAMIN, 1987, p. 206) Esta ideia pode ser traduzida nas sábias palavras de Mestre Bigo: "Para chegar em Angola é longe." Para quem não entendeu: não se aprende capoeira 
em pouco tempo, o conhecimento envolvido nessa arte é maior do que uma simples e aparente movimentação corporal. A sabedoria da capoeira demanda um longo e lento aprendizado. "Para chegar em Angola é longe."

Entendemos que a capoeira, devido a sua forma de propagação oral, impõe a proximidade entre mestre e discípulo, fazendo desta proximidade o método de ensino para além de qualquer metodologia institucional. "O grande narrador tem sempre suas raízes no povo, principalmente em suas camadas artesanais." (BENJAMIN, 1987, p. 214)

Paulo Freire, ao tratar daquilo que chamou de educação popular, enfatiza alguns aspectos presentes na cultura popular que vemos também na capoeira. $\mathrm{O}$ autor apresenta a tradição oral como forma de transmissão de sabedorias $e$ experiências e enfatiza o caráter popular desta tradição no Brasil. Assim, afirma que o método popular é oral, não escrito e é pouco conceitualizado do ponto de vista formal.

Objetos, situações e acontecimentos são oralmente assumidos por ele [povo], assumidos como narrativa. Nossa tradição na cultura popular é mais oral do que escrita. As pessoas fazem narrações orais. E o que é narrado exige troca de olhares e gestos. (FREIRE, 1981, p.28)

Freire chama ao mestre da cultura de intelectual popular. A cultura popular refina, educa, produz mestres, diz. De fato, a proximidade com um mestre, seja de capoeira, de bateria de escola de samba, de jongo, de maracatu, etc. deixa claro que a sabedoria popular brasileira aí reside com toda força e é mantida pela tradição oral. Se compararmos essa tradição existente hoje no Brasil, com o pessimismo de Walter Benjamin ao falar das narrativas e das experiências, podemos ter um pouco melhor a noção do tamanho da riqueza de que somos herdeiros. Riqueza essa disponível, em geral, de graça e na rua. Porém muito pouco valorizada pelo status quo cultural e pelas instituições responsáveis pela sua reprodução.

Na capoeira, a transmissão dos conhecimentos se dá pela proximidade do discípulo com o mestre. A figura do mestre é imprescindível à formação do capoeirista. Neste sentido, a capoeira, enquanto educação popular traz, pela 
oralidade e proximidade aos mais velhos praticantes da arte, o respeito pelas gerações mais velhas e por tudo o que elas fizeram.

Isto significa que deve-se acrescentar a esta presença da capoeira na escola a educação popular, como a entende Freire, fortalecendo a proximidade dos estudantes e, talvez principalmente dos professores, com um Mestre ou professor de capoeira. Relação esta que, devido a tudo o que foi falado sobre cultura popular oral, é a porta de entrada da criança no mundo da cultura popular brasileira de matriz africana. Cultura essa a qual talvez nunca venha a ser apresentada ou, quando o for, o será da forma estereotipada, como os meios formais de comunicação frequentemente o fazem.

A preocupação com a formação das novas gerações caminha pari passu com o respeito aos mais velhos, por sua experiência e sua luta. Os saberes, pautados na transmissão oral, necessitam de alguém que tenha tempo e experiência de vida para transmitir ensinamentos. Por isso, é forte a figura do mestre que traduz a capoeira como filosofia, na qual as histórias dos mais velhos orientam a vida dos mais jovens. (BRASIL, 2014, p.94)

Cremos que a inserção da capoeira na educação escolar deve se dar não como algo curricular, fechado em disciplinas como Educação Física, nem deve aparecer como folclore. Existem inúmeros grupos de capoeira espalhados pelo Brasil, defendemos que haja cada vez mais interação entre as escolas e esses grupos. Uma prática hoje muito comum é a escola abrir seu espaço físico para que um grupo de capoeira desenvolva seu projeto como atividade extracurricular. Essa excelente prática já mostra que a capoeira sempre soube sobreviver se inserindo da melhor forma possível nos espaços de onde sempre fora excluída. A mandinga faz parte de sua essência.

\section{Relato de experiência em fase inicial: o Grupo de Capoeira Angolinha e os Projetos de Capoeira Angola na universidade e na escola}

Os temas aqui tratados, a lembrar, ancestralidade, historicidade, tradição cultural popular, proximidade com mestres de sabedoria popular são temas fortemente atrelados à capoeira e podem ser inseridos no cotidiano dos estudantes, 
de todos os níveis: fundamental, médio e universitário, como são os casos do Grupo de Extensão da Universidade Federal Rural do Rio de Janeiro "Grupo de Capoeira Angolinha", do projeto de Capoeira Angola no Colégio Estadual Euclydes da Cunha, em Teresópolis RJ e do Projeto "Capoeira de Angola", desenvolvido dentro do Programa de Extensão e Pesquisa "Áfric(a)ção", na UFRJMacaé. A seguir, faremos uma rápida apresentação de cada um.

O Grupo de Capoeira Angolinha é um grupo de capoeira que possui sua sede na UFRRJ e já existe há quinze anos. Neste período já foram formados um contramestre, vários professores e trenéis, assim como muitos alunos por ali passaram. As experiências e importância deste grupo na vida dos estudantes universitários foram estudadas em dissertação de mestrado defendida por Amanda Schütte, no mestrado em educação da UFF, sob o título "Capoeirando a educação". (Gustavo Camargo participa do Grupo de Capoeira Angolinha desde 2001 e Amanda Shütte desde 2008)

O projeto de "Capoeira Angola" no Colégio Estadual Euclydes da Cunha em Teresópolis é coordenado por Amanda Schutte, que é também professora de Educação Física do colégio. Este projeto completou um ano em 2016 e gerou alguns encontros e oficinas com o Mestre Angolinha, contramestre Japa e outros professores do Grupo de Capoeira Angolinha, rodas na escola e na feira Agroecológica no centro da cidade e apresentação no programa Cultura de Raiz que tem a iniciativa da Secretaria de Cultura de Teresópolis.

O Projeto "Capoeira de Angola", na UFRJ-Macaé, coordenado pelo professor Gustavo Camargo (Peninha), consiste na organização de um grupo de Capoeira Angola no bairro Barreto, bairro pobre onde se situa um polo da universidade, e é composto por professores, estudantes, técnicos administrativos e moradores do bairro. Junto ao desenvolvimento das atividades comuns de capoeira, como treinos, aprendizados de instrumentos e realização de rodas, há a realização de oficinas com o Mestre Angolinha e a apresentação de oficinas e rodas de conversa em escolas. São parceiros deste Projeto a Associação de Moradores do Bairro Barreto e o Grupo de Capoeira Angolinha, coordenado pelo Mestre Angolinha. Neste projeto, até agora, já foram realizadas duas oficinas com o 
Mestre Angolinha, proporcionando a todos o contato mais próximo com um mestre da cultura popular, assim como muitos alunos vão ao Rio de Janeiro participar de eventos de capoeira e cultura e, consequentemente, se aproximam dos mestres.

Ao entender capoeira como filosofia de vida, Mestre Angolinha apresenta em toda sua força a inseparabilidade entre arte e vida, e a força da capoeira como arte no caso particular de sua vida. Para o capoeirista, não apenas o praticante de capoeira, esta arte é indistinguível de seu viver cotidiano.

\section{REFERÊNCIAS}

BENJAMIN, W. "Sobre o conceito de história". Tradução de Sérgio Paulo Rouanet. Em: "Obras escolhidas. Vol. 1. Magia e técnica, arte e política. Ensaios sobre literatura e história da cultura." São Paulo: Brasiliense, 1987, p. 222-232.

. "O narrador: considerações sobre a obra de NIkoli Leskov". Em: "Obras escolhidas. Vol. 1. Magia e técnica, arte e política. Ensaios sobre literatura e história da cultura." São Paulo: Brasiliense, 1987, p. 197-221.

. "Experiência e pobreza". Em "Obras escolhidas. Vol. 1. Magia e técnica, arte e política. Ensaios sobre literatura e história da cultura." São Paulo: Brasiliense, 1987, p. 114-119.

BRASIL. Ministério da Educação. Secretaria de Educação Continuada, Alfabetização, Diversidade e Inclusão. "História e cultura africana e afro-brasileira na educação infantil" / Ministério da Educação. Secretaria de Educação Continuada, Alfabetização, Diversidade e Inclusão. -- Brasília : MEC/SECADI, UFSCar, $2014 . \quad$ Disponível em: http://etnicoracial.mec.gov.br/images/pdf/publicacoes/Histria\%20e\%20cultura\%20a fricana\%20e\%20afro-brasileira\%20na\%20educao\%20infantil.pdf

CASTRO JR., L.V. "Capoeira Angola: olhares e toques cruzados entre historicidade e ancestralidade". Revista Brasileira de Ciências do Esporte. V. 25. N. 2, p. 143158, jan. 2004. Em: http://rbce.cbce.org.br/index.php/RBCE/article/view/232

. "Oralidade, discursos e saberes do corpo-capoeira como arte".

Revista Fenix: Revista de História e estudos culturais. Vol. 9, ano: IX, N. 3, 2012. Em: http://www.revistafenix.pro.br/vol30luis.php

FREIRE, P. "Educação cultural para a liberdade". $5^{\text {a }}$ ed., Rio de Janeiro, Paz e Terra. 1981.

GAGNEBIN, J.M. "História e narração em Walter Benjamin". Ed. Perspectiva, São Paulo, 1999.

MURICY, K. “Alegorias da dialética”. Relume Dumará. Rio de Janeiro, 1999. 
NOGUEIRA, R. "O ensino de filosofia e a Lei 10.639". Pallas editora. $1^{\mathrm{a}}$ ed. Rio de Janeiro, 2014.

OLIVEIRA, E.D. "Filosofia da ancestralidade como filosofia africana: educação e cultura afro-brasileira". Revista Sulamericana de filosofia da educação (RESAFE) Número 18, maio-outubro de 2012, 28-47. Em: http://periodicos.unb.br/index.php/resafe/article/view/7029

RAMOSE, M.B. "Sobre a legitimidade e o estatuto da filosofia africana". Ensaios Filosóficos, Volume IV, outubro de 2011. Em: http://www.ensaiosfilosoficos.com.br/Artigos/Artigo4/RAMOSE MB.pdf

SANTOS, Luis Carlos. "Ancestralidade e liberdade: Em torno de uma filosofia africana no Brasil". Revista Sul-Americana de Filosofia e Educação. Número 18: maio-out/2012, p. 48- 61.

SCHÜTTE, A. "Capoeirando a educação". Dissertação de mestrado. UFF. Niterói, 2015. Inédita.

SILVA e HEINE, "Capoeira e inclusão social" em ITAMARATY. "Textos do Brasil." Edição número 14: Capoeira. Sem data. Disponível em: http://dc.itamaraty.gov.br/imagens-e-textos/revista-textos-dobrasil/portugues/edicao-no-14-capoeira. Acesso em 3/06/2015

ZERBO, J.K. "História geral da África, I: Metodologia e pré-história da África" / editado por Joseph Ki-Zerbo. - 2.ed. rev. - Brasília : UNESCO, 2010. Disponível em:http:/www.dominiopublico.gov.br/pesquisa/DetalheObraForm.do?select_action $=\&$ co obra $=205171$. Acesso em: 15/07/2015 